\title{
15-Min Station: A Case Study in North Italy City to Evaluate the Livability of an Area
}

\author{
Fabio Borghetti ${ }^{1}\left(\mathbb{D}\right.$, Cristian Giovanni Colombo $^{2}\left(\mathbb{D}\right.$, Michela Longo $^{3, *} \mathbb{(}$, Renato Mazzoncini ${ }^{4}$, \\ Leonardo Cesarini ${ }^{5}$, Luigi Contestabile ${ }^{6}$ and Claudio Somaschini ${ }^{7}$ (i)
}

1 Mobility and Transport Laboratory, Design Department, Politecnico di Milano, 20133 Milano, Italy; fabio.borghetti@polimi.it

2 Department of Research and Development, Fondazione Politecnico di Milano, 20133 Milano, Italy; cristiangiovanni.colombo@fondazione.polimi.it

3 Department of Energy, Politecnico di Milano, 20133 Milano, Italy

4 A2A S.p.A., 20122 Milano, Italy; renato.mazzoncini@polimi.it

5 Department of Research and Development, TRENORD S.r.L., 20123 Milano, Italy; leonardo.cesarini@trenord.it

6 Department of Research and Development, Rete Ferroviaria Italiana S.p.A., 00161 Roma, Italy; 1.contestabile@rfi.it

7 Department of Mechanical Engineering, Politecnico di Milano, 20133 Milano, Italy; claudio.somaschini@polimi.it

* Correspondence: michela.longo@polimi.it; Tel.: +39-2399-3759

\section{check for} updates

Citation: Borghetti, F.; Colombo, C.G.; Longo, M.; Mazzoncini, R.; Cesarini, L.; Contestabile, L.; Somaschini, C. 15-Min Station: A Case Study in North Italy City to Evaluate the Livability of an Area. Sustainability 2021, 13, 246. https:/ / doi.org/10.3390/su131810246

\section{Academic Editors:}

Benedetto Barabino, Cristian Lai and Giulio Maternini

Received: 6 August 2021

Accepted: 12 September 2021

Published: 14 September 2021

Publisher's Note: MDPI stays neutral with regard to jurisdictional claims in published maps and institutional affiliations.

Copyright: (c) 2021 by the authors. Licensee MDPI, Basel, Switzerland. This article is an open access article distributed under the terms and conditions of the Creative Commons Attribution (CC BY) license (https:// creativecommons.org/licenses/by/ $4.0 /)$.

\begin{abstract}
The goal of this work is to apply the idea of the city in $15 \mathrm{~min}$ to railway stations that can become the starting point of the analysis as they represent the "gateway", where users start their last mile of travel after getting off the train. Within the research, 11 railway stations located in the Lombardy Region in Italy were identified and analyzed. To perform the analysis, an analytical index was implemented and determined for each station: this index summarizes the main features of the station itself in relation to the territory in which it is located. The adopted approach is comparative: it is not important the absolute value of the index of each station, but the comparison between the different indices. In this way it is possible on the one hand to classify the stations and on the other hand to identify and propose possible interventions to improve the role of a railway station in a territory. The proposed model is expandable and replicable: it is possible to add other useful indicators for the calculation of the index of each station and it is also possible to perform the analysis in different territorial contexts. In fact, it is a decision support tool able to provide indications and information for the planning and programming of the railway system and of the city; among the potential users of the proposed model there are railway station managers and administrations.
\end{abstract}

Keywords: 15-min stations; mobility; smart mobility; urban mobility; transportation; transportation planning; railway station; environmental sustainability; GIS; cities

\section{Introduction}

In recent years, major metropolises are becoming more sustainable cities with all services within 15 min of home: this is an innovative urban policy focused on environmental sustainability. This approach goes hand in hand with the current energy transition towards decarbonization centered on sustainable energy and innovative/digital services. This transformation is taking place through partnerships between different players including companies, administrations, and communities [1,2].

The idea is a new urban space that respects the environment on the one hand and on the other responds to the need to reduce crowds and mass movements during peak hours. It is an idea of an eco-sustainable city that today more than ever due to the COVID-19 emergency is developing reopening the debate on how to rethink urban spaces $[3,4]$. 
The city in 15 min comes from the idea that each person should be able to reach in maximum fifteen minutes from home all services related to work, food, housing, health, education, culture, and leisure $[5,6]$.

This represents an innovative approach to the idea of smart city in which the need of the citizen plays a central role in order to offer, within each neighborhood, everything you need; to support this urban revolution there is the use of new technologies.

The city models that have spread in recent years have shown several criticalities: for example, in order to reach the various essential services and the workplace, long journeys on public transport and in urban traffic are necessary. In this perspective, the railway station can play a key role in the re-planning of the city and urban spaces [7].

The choice of the city in $15 \mathrm{~min}$ is also sustainable from an environmental point of view. The possibility of having the necessary services, including, for example, the workplace, close to one's home would reduce the emissions produced by travel within the city, thus reducing urban congestion. In addition to the lower impact in environmental terms, there is also an improvement in the quality of life. The proximity allows, in fact, to avoid queues and congestion typical of peak times in large cities [8,9].

An additional benefit is less stress caused by the city chaos and a saving of time that could be dedicated to personal hobbies and interests.

In Europe, urban areas represent the "engine" of economic growth and land employment: European cities generates around 85\% of the EU's GDP (Gross Domestic Product). Many European cities, due to extensive economic activities in urban areas, face and manage transport and mobility related problems such as congestions, air pollution, safety and noise pollution. In 2010, for instance, around $73 \%$ of European citizens lived in urban areas; it is estimated that this percentage will increase over than the $80 \%$ by 2050 [10]. In addition to the direct impact generated by traffic, urban mobility can also influence social development, social exclusion and accessibility for people with reduced mobility. Consequently, the need to adopt sustainable transport systems is now a global goal that can no longer be postponed.

Starting from these considerations, the aim of this work is to apply the idea of the city in 15 min to railway stations: in this perspective, the railway station becomes the starting point of the analysis as it represents the "front door", where users start their last mile journeys after getting off the train (Figure 1). In this way, infrastructure and transport policy is seen as a useful tool for increasing social cohesion and improving the integration of citizens in a territory [11].

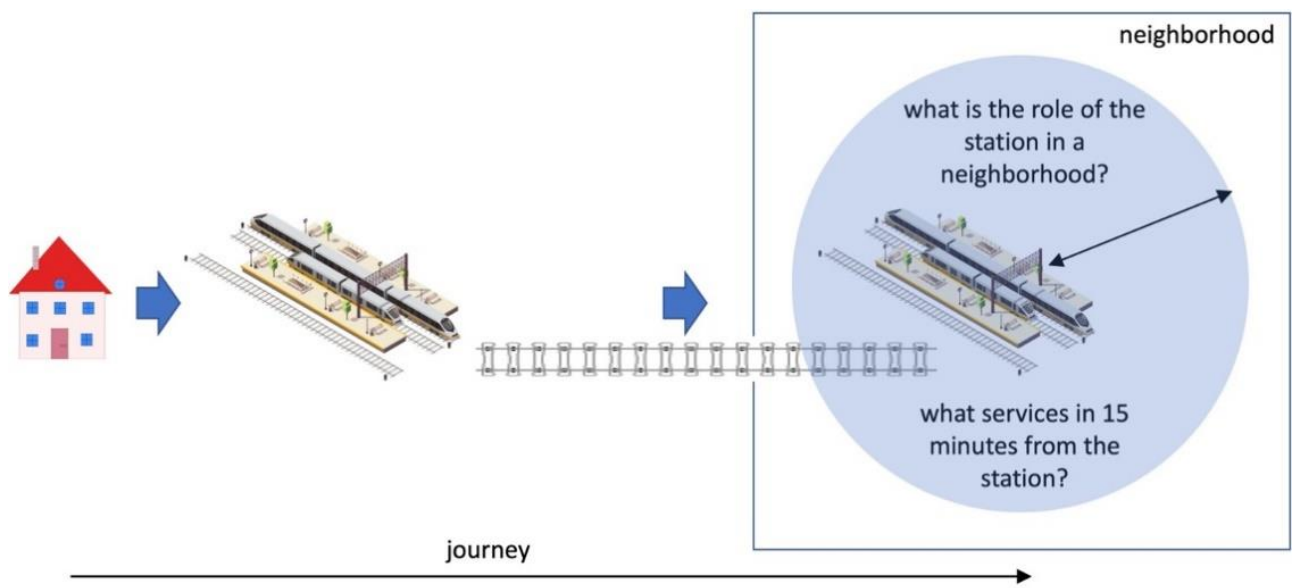

Figure 1. The idea of 15-Minutes City to railway station.

For some railway stations located in northern Italy, an analytical index has been defined that summarizes the characteristics of the station in relation to the territory in which it is located. In this way it is possible on the one hand to classify the stations and on the other to identify and propose improvements aimed at relaunching the role of a railway 
station in a territory. This work represents a preliminary study to begin to address the issue linked to the centrality of railway stations in the development of an urban area. The paper is organized as follows: a first part analyzes the background with particular reference to the elements of transport system planning and the basic concepts of the city in 15 min; then the case study in Lombardy Region is presented with the analysis of the 11 selected stations; the third paragraph concerns the calculation of the analytical index starting from gravitational models of scientific literature; in the fourth paragraph the results obtained are analyzed and discussed and finally the conclusions of the work done are presented.

\section{Background}

A key element within the discipline of transportation planning is the definition of transportation system. It is difficult to provide a single definition of a transport system: a transport system can be defined as a set of elements and their interactions that generate both the travel demand (mobility need) within a given area (territory) and the transport services to satisfy this demand (need) [12].

When we talk about transport and mobility it is also necessary to introduce the concept of territory: transport and territory are strongly connected and especially interdependent. The territory influences the transport system and vice versa. From a theoretical point of view, the transport system is made up of two main elements: the demand and the supply of transport as shown in Figure 2 [13].

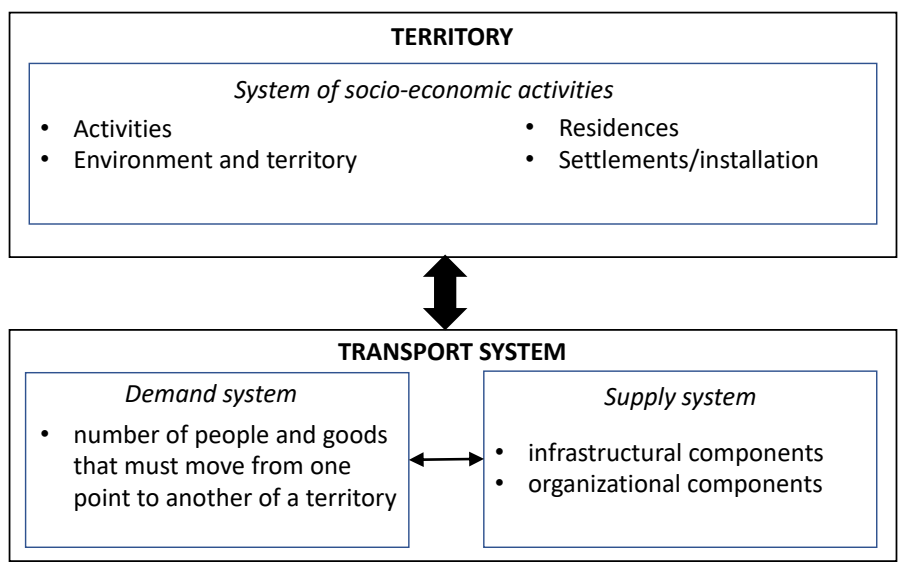

Figure 2. Relationships between the transport system and the territory.

Transportation demand is closely related to the mobility needs of a group of people in an area (e.g., a neighborhood, a city, etc.) while transportation supply is primarily comprised of infrastructure (roads, rail lines, trolley lines, parking lots, ports, airports, etc.) and services (regulations, transit schedules, fares, parking fees, road tolls, etc.) [14,15].

The system of activities is in fact the set of individual, social and economic behaviors and interactions that give rise to the transport demand (reason for travel).

The sustainability transition leads to new experiments different from the past decade, where studies lack spatial consideration. The outputs and outcomes of these experiments can change, depending on how they are designed in the first place $[16,17]$. In fact, some questions coming from the modern mobility world are neighbouring with other world such as urban planning: how the environment of public space affects the sustainability of urban mobility in contemporary cities and how does facilitating mobility contribute to the liveability of the public realm, are only two examples of them $[18,19]$.

Urban sprawl, observed in several countries around the world, is now considered harmful to the liveability and sustainability of the city $[20,21]$ : this situation causes some externalities, including longer journeys within the city, increased use of private cars, congestion, and pollution [22-24]. Different studies have addressed the relationship between mobility within cities and the city, creating a debate on the size and optimal structure of 
cities [25-27]. To promote sustainable mobility models, current strategies have used smart growth interventions to move from monocentric city structures to developing polycentric and more localized [28,29].

Strategies that promote polycentricity aim to increase the supply of local services, such as schools, public transport options, health facilities, food and beverage outlets, workplaces, recreation areas and retail stores, by creating local areas that are sustainable, inclusive, and walkable within a short distance [30]. With this focus, some research reduces the need to find and design neighbourhoods at scale to improve local accessibility, adapt travel behaviours and car ownership and mileage [31,32]. The creation of attractive public spaces, (which are also mobility hubs e.g., stations, airports, bus stops, intermodal terminals), and the use of streets with sidewalks and bike lanes (e.g., walking and cycling) represent a key factor for the design of sustainable mobility systems and the creation of sustainable and liveable cities [33].

The idea of the city of $15 \mathrm{~min}$ is gradually growing in importance from both a political and a social point of view. The basis of the idea is the promotion of interventions to increase the supply of local services, such as schools, public transport systems, health facilities, food courts, workplaces, recreation areas and retail shops [16]. In this way, the local areas are to be more sustainable, inclusive, and passable in a small radius on foot or by bicycle. Several international organizations (e.g., OECD, EEA, World Bank and UN-HABITAT) have already developed a set of indicators as tools for assessing urban sustainability $[34,35]$. In developing variables able to describe both environmental and socio-economic issues, these organizations have established both the availability of public spaces (quantitative) and the degree to which inhabitants use public transportation or non-motorized transport as indicators. Therefore, public spaces can be a key factor for the sustainable and liveable city of the future; more tools need to be developed to evaluate better their importance to achieve urban sustainability. Figure 3 summarizes the concept of 15 min City with its 4 components/dimensions: Density, Proximity, Diversity and Digitization. Furthermore, the relationship with the transport system and the socio-economic system of an area is illustrated in Figure 3 [36,37].

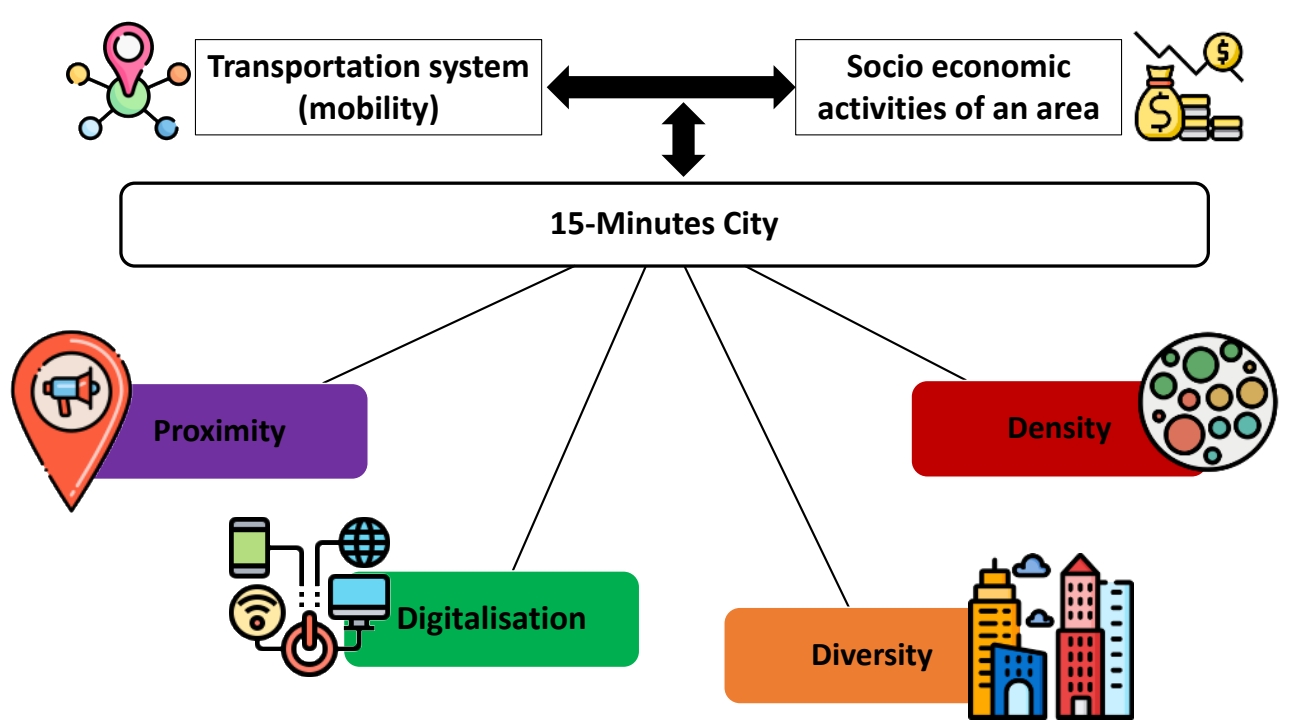

Figure 3. The 15-Min City components and relationship with transportations system and socioeconomic activities of an area.

In the area of sustainable mobility, it may be useful to report on an approach that fits well with the 15-min city concept and focuses on people's mobility needs rather than transportation infrastructure. This approach is known as A-S-I and is based on three basic components: Avoid/Reduce, Shift/Maintain, Improve. The main goal is to significantly 
reduce greenhouse gas emissions, energy consumption, traffic congestion and create more livable cities.

The first component, Avoid/Reduce, is aimed at improving the efficiency of the transportation system as a whole. The basis is the idea that the need for motorized journeys and the length of journeys can be reduced through compact development of cities and by taking into account existing transportation systems. The goal is to remodel transportation demand: for example, residential, work, and entertainment districts should become more closely connected.

The second component, Shift/Maintain, aims to improve the efficiency of individual travel. Specifically, it aims to change the modal split of journeys, shifting users' choices from a more polluting and energy-intensive mode of urban transport (e.g., the endothermicengine car) to more environmentally friendly modes. There are, for example, two possible modes of travel, especially in urban areas: (i) on foot or by bicycle, (ii) by public transport. Walking and/or cycling is one of the most effective and environmentally friendly options for increasing sustainable mobility. Although mass transit, such as trolley buses, tramways, buses, and railways, can also generate emissions, the lower specific energy consumption per passenger-km and high occupancy rate (people $/ \mathrm{m}^{2}$ ) mean that the associated $\mathrm{CO}_{2}$ emissions per passenger-km are lower than those of car use. Some developing countries, for this reason, are incentivizing and investing in these two modes of transport.

The last component, Improve, concerns the efficiency of vehicles, fuel and operational management of public transport; the aim is to identify and adopt strategies to make public transport increasingly attractive and competitive. With this in mind, attention must be paid to the energy sources required for the operation of transport systems: the introduction and use of renewable energy sources must become a fundamental principle $[38,39]$.

\section{Case Study}

The work purpose is the analysis of the "15 min city" concept implementing a case study to assess how a railway station is or could be a potential point of interest in an urban area. The case study is performed to answer the following questions:

- What is the actual situation of the railway station identified?

- What could be done in the future in order to increase the liveability of the area?

In the following sections, a general description of the approach performed has been described to find an answer at two questions. After that, a possible tool for an easy and fast evaluation of the station's compatibility with the "15 min city" concept has been described.

\subsection{Study Area}

The Lombardy region is located in Northern Italy and due to its large extension, it is impossible to consider all the 400 stations located in the overall study area. For this reason, it is established to focus the analysis on 11 railway stations, which are considered representative [40].

\section{Criteria of Stations Selection}

The choice criteria to select the 11 railway stations considered, is based on the number of daily passenger flow of the stations, this data was obtained from a database available on OpenData Lombardia website [41]. This database contains, for each station, the number of passengers alighted and got off the trains during the morning peak hours (h 7-9) and during the entire $24 \mathrm{~h}$. The day taken as reference is a standard working day of November 2019.

In order to extract the list of the selected stations, it was not only used the overall passengers flow but also the geographical location of the station. In fact, considering only the net flow of passenger in the morning rush hour, only stations located in the metropolitan area of Milan would appear as clear poles of attraction (more passengers got off the train than got in). 
This, however, would result in an unbalanced scenario since the original analysis should be focused on the entire Lombardy region. Therefore, the choice of the stations was done considering both attraction and emission poles. Attraction poles are mostly located in Milan and other big cities, whereas emission poles are usually peripherical stations. Moreover, big stations like Milano-Porta Garibaldi and Milano Centrale were not included in the final list, because it was believed that these are extraordinary scenarios that need peculiar and independent analysis due to the relevant number of parameters that affect their surrounding neighborhood.

As it can be seen from Figure 4, a homogeneous distribution of the 11 stations in the study area was reached, obtaining a good choice mix between passenger's flow and geographical location.

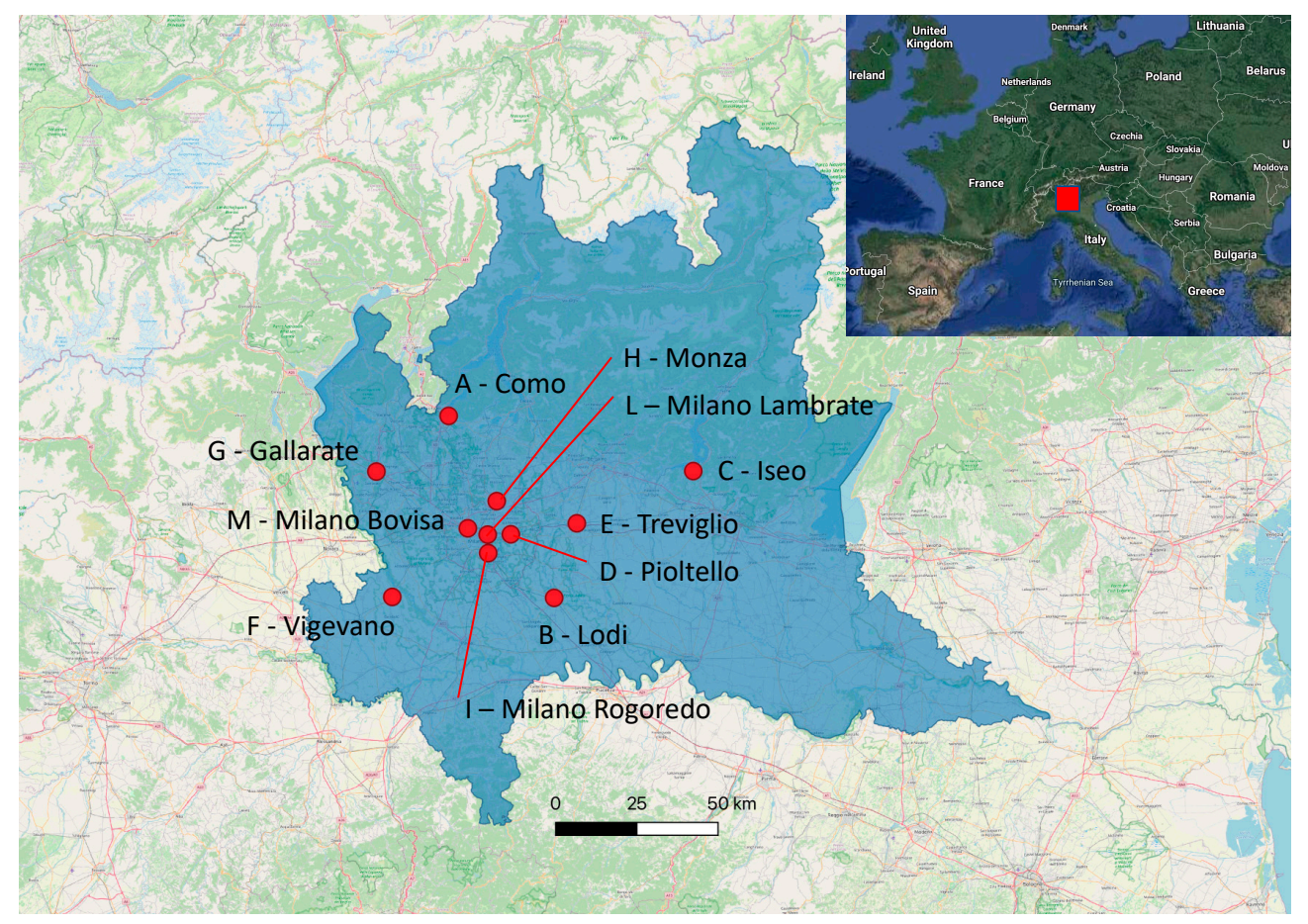

Figure 4. Lombardy region location and chosen 11 railway stations for the analysis.

\subsection{Analysis of the Current Scenario}

Once the list of stations of interest was defined, in order to define the as-is scenario in the study area two different types of analysis were performed. One directed towards the area around the station (Territorial Analysis) reachable in $15 \mathrm{~min}$ and the other one inside the station (Station Interior Analysis).

First, an analysis on passenger's trip motivation and population density was performed, to better understand the kind of traffic flow, which characterizes each station and the surrounding city context. These analyses were performed with the help of data coming from the 2016 OD-Origin Destination Matrix from OpenData Lombardia and the latest ISTAT-Instituto Nazionale di Statistica census (2011) [42].

Figure 5 shows the different reasons of trip in all the stations of the case study. 


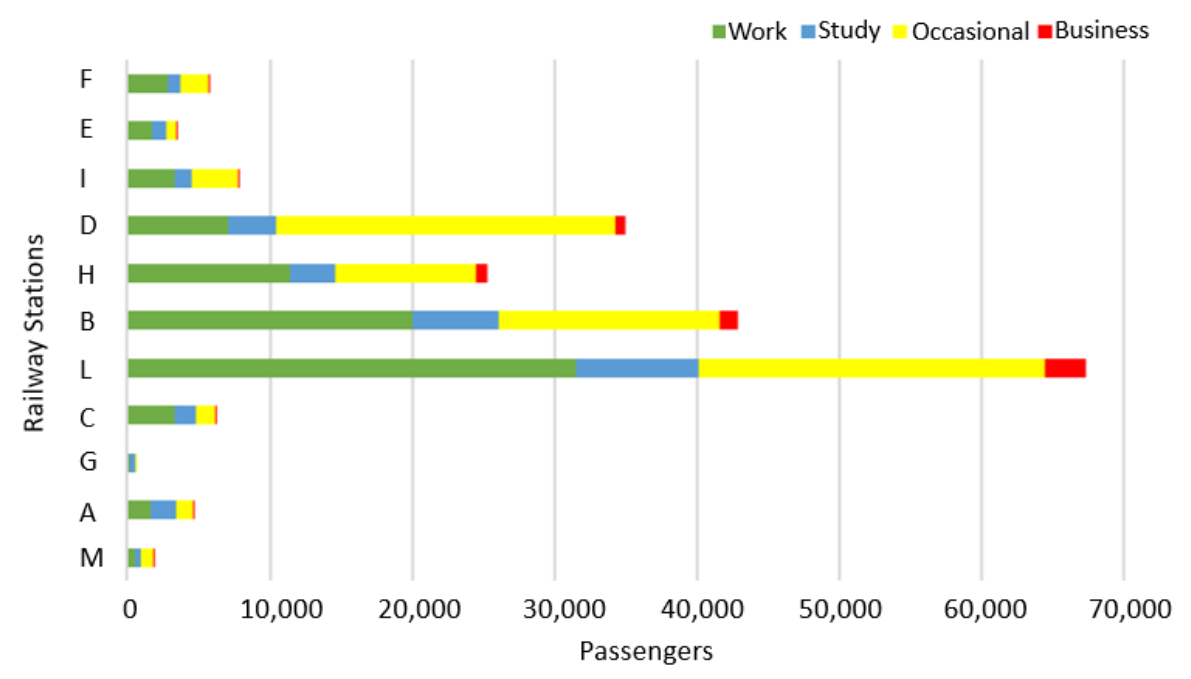

Figure 5. Reason of trips for all the analyzed railway stations.

\subsection{Territorial Analysis}

The types of services investigated come from a preliminary analysis consistently to the "15 min" thinking and the data availability. There is a high number of services evaluable or feasible, but it was decided to focus the attention of analysis on a reduced number of them.

The services selected follow the "15 min" concept, namely the possibility to have at disposal all the essential services of the everyday life within a 15-min walking radius (about $850 \mathrm{~m}$ ). These services presence can potentially increase the environment value around the station allowing a better integration in the urban fabric.

As a result, the following list of services were analyzed:

- H: Hospitals

- PO: Post Offices

- S: Schools

- SM: Supermarkets

- PH: Pharmacies

- TC: Theatres and Cinemas

- P: Pubs

- CB: Cafè and Bars

- R: Restaurants

- EV_CS: EV charging points

- L: Libraries

- CP: Car parking

Geo-referenced data coming from OpenStreetMap portal and ISTAT were used to investigate the area around the stations of interest. Then, these data were elaborated through QGIS, an open-source GIS (Geographic Information Systems) software.

After the geo-localization of the rail station, the first action performed was uploading in the QGIS project of all the geo-referenced files related to services (bars, restaurants, cinemas, hospitals etc.) coming from OpenStreetMap and the census data coming from ISTAT. This operation result is reported in Figure 6. After that, exploiting the ORS Tool plug-in, the 15 min walking isochrone was plotted, to highlight the services in line with the "15 min city" concept. This threshold helps to separate the services available within the $15 \mathrm{~min}$ basin from the ones that lay outside. 


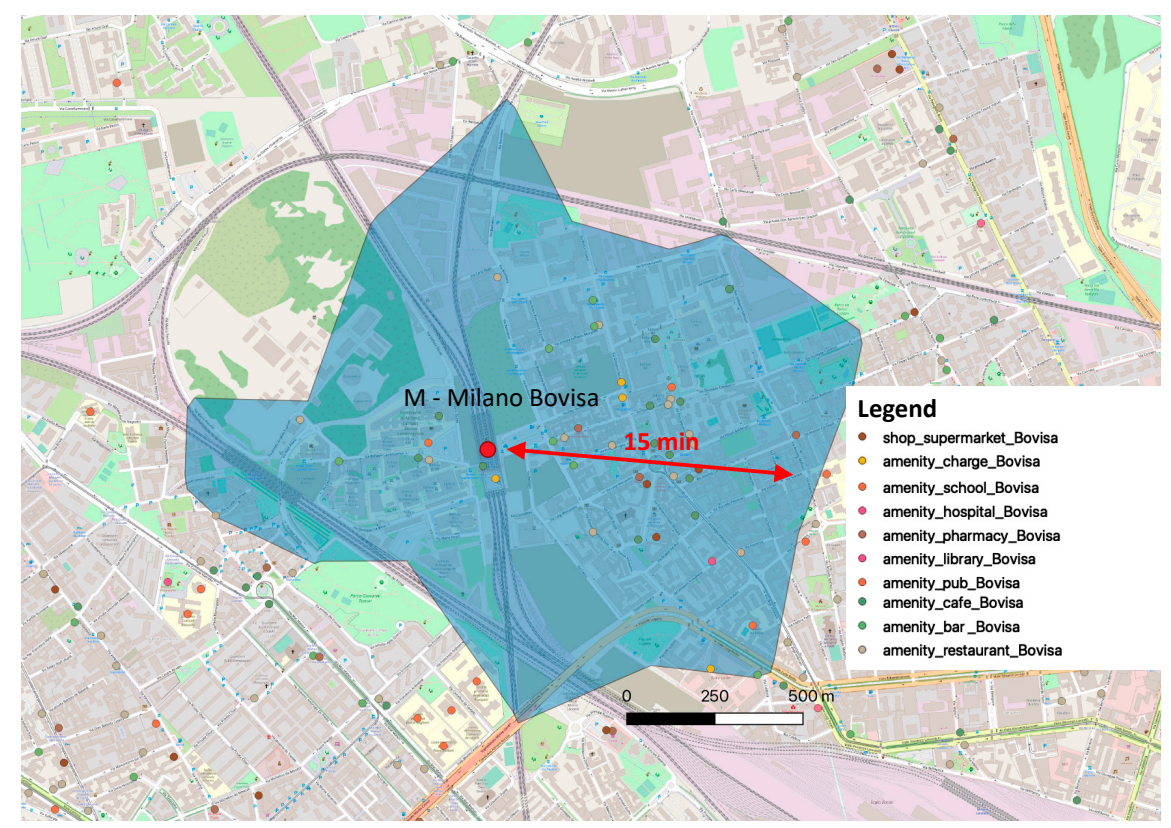

Figure 6. Example of $15 \mathrm{~min}$ isochrone to identify the services-points of interest near the railway station.

This analysis was performed for all the stations taken into consideration where the correspondence is reported in Figure 4. Table 1 shows the number of services (described above in the bulleted list) within the $15 \mathrm{~min}$ isochrone for each chosen station. As reported in Table 1, stations that are heavily congested such as Milano Bovisa (M), Milano Lambrate $(\mathrm{L})$ and Monza $(\mathrm{H})$, present a high number of cafes and restaurants. This is probably related to the high number of passengers which cross these stations for work and study purposes. On the opposite side, a critical node like Milano Rogoredo (I) presents a not significant number of these amenities compared to its passenger's flow. This might be due to the low urban development of the area or degraded or unsafe environment around the station that do not enhance the urban development.

Table 1. Number of services falling into the 15-min basing for each railway station.

\begin{tabular}{|c|c|c|c|c|c|c|c|c|c|c|c|}
\hline \multirow{2}{*}{ Services } & \multicolumn{11}{|c|}{ Railway Stations Analyzed } \\
\hline & $\mathbf{A}$ & B & $\mathrm{C}$ & D & $\mathbf{E}$ & $\mathbf{F}$ & G & $\mathbf{H}$ & I & $\mathbf{L}$ & $\mathbf{M}$ \\
\hline $\mathbf{H}-$ Hospitals & 1 & 0 & 1 & 0 & 0 & 1 & 1 & 0 & 0 & 1 & 0 \\
\hline PO_-Post Office & 3 & 2 & 0 & 1 & 2 & 1 & 2 & 2 & 1 & 4 & 0 \\
\hline S-Schools & 4 & 16 & 2 & 1 & 3 & 8 & 7 & 8 & 2 & 9 & 3 \\
\hline SM-Supermarkets & 4 & 4 & 3 & 2 & 4 & 0 & 4 & 6 & 1 & 11 & 3 \\
\hline PH-Pharmacies & 7 & 7 & 1 & 0 & 4 & 5 & 10 & 12 & 3 & 12 & 3 \\
\hline L-Libraries & 2 & 1 & 0 & 1 & 0 & 1 & 1 & 2 & 0 & 1 & 0 \\
\hline $\begin{array}{c}\text { TC - Theatres and } \\
\text { Cinemas }\end{array}$ & 2 & 4 & 0 & 0 & 2 & 2 & 4 & 4 & 0 & 2 & 0 \\
\hline P-Pubs & 1 & 1 & 1 & 0 & 1 & 2 & 4 & 2 & 1 & 9 & 0 \\
\hline CB-Cafè and Bars & 51 & 52 & 6 & 2 & 11 & 9 & 57 & 63 & 15 & 74 & 18 \\
\hline R-Resturants & 70 & 14 & 8 & 1 & 6 & 5 & 36 & 46 & 16 & 46 & 13 \\
\hline $\begin{array}{c}\text { EV_CS_EV charging } \\
\text { points }\end{array}$ & 5 & 0 & 1 & 0 & 4 & 1 & 4 & 2 & 2 & 4 & 3 \\
\hline
\end{tabular}

A = Como; B = Lodi; C = Iseo; D = Pioltello; $\mathrm{E}$ = Treviglio; $\mathrm{F}$ = Vigevano; $\mathrm{G}$ = Gallarate; $\mathrm{H}$ = Monza; L = Milano Lambrate; $\mathrm{M}=$ Milano Bovisa.

It was interesting that a station like Lodi (B) has a significant number of schools, cafés and restaurants, with respect to the passengers' flow. This can be considered as an indicator 
that the railway station in Lodi (B) could become an attractive pole for local residents, students, and leisure.

Finally, results from touristic sites like Como (A) and Iseo (C) show a substantial difference in service availability, with the latter often offering no services on several occasions. This is related to the different traffic volume, but also to the size of the city itself.

\subsection{Station Interior Analysis}

The aim of this analysis is to give an idea on the situation inside the stations, in order to highlight what is present and what is still missing for future evaluation. The services present in the reference stations have been reported in Table 2.

Table 2. Services available inside the 11 railway stations analysed.

\begin{tabular}{|c|c|c|c|c|c|c|c|c|c|c|c|}
\hline & $\mathbf{A}$ & B & $\mathrm{C}$ & D & $\mathbf{E}$ & $\mathbf{F}$ & G & $\mathbf{H}$ & I & L & $\mathbf{M}$ \\
\hline $\begin{array}{c}\text { Café } \\
\text { Bike storage }\end{array}$ & $\sqrt{ }$ & $\sqrt{ }$ & $\sqrt{ }$ & $\sqrt{ }$ & $\begin{array}{l}\sqrt{ } \\
\sqrt{ }\end{array}$ & $\sqrt{ }$ & $\sqrt{ }$ & $\sqrt{ }$ & $\sqrt{ }$ & $\sqrt{ }$ & $\sqrt{ }$ \\
\hline Bike parking & $\sqrt{ }$ & $\sqrt{ }$ & $\sqrt{ }$ & $\sqrt{ }$ & $\sqrt{ }$ & $\sqrt{ }$ & $\sqrt{ }$ & $\sqrt{ }$ & $\sqrt{ }$ & $\sqrt{ }$ & $\sqrt{ }$ \\
\hline Car parking & $\sqrt{ }$ & $\sqrt{ }$ & $\sqrt{ }$ & $\sqrt{ }$ & $\sqrt{ }$ & $\sqrt{ }$ & $\sqrt{ }$ & $\sqrt{ }$ & $\sqrt{ }$ & $\sqrt{ }$ & $\sqrt{ }$ \\
\hline Ticket mach./off. & $\sqrt{ }$ & & $\sqrt{ }$ & & $\sqrt{ }$ & $\sqrt{ }$ & $\sqrt{ }$ & $\sqrt{ }$ & $\sqrt{ }$ & $\sqrt{ }$ & $\sqrt{ }$ \\
\hline Waiting room & & $\sqrt{ }$ & $\sqrt{ }$ & & & $\sqrt{ }$ & $\sqrt{ }$ & & & $\sqrt{ }$ & $\sqrt{ }$ \\
\hline Toilets & $\sqrt{ }$ & $\sqrt{ }$ & $\sqrt{ }$ & $\sqrt{ }$ & $\sqrt{ }$ & $\sqrt{ }$ & $\sqrt{ }$ & $\sqrt{ }$ & $\sqrt{ }$ & $\sqrt{ }$ & $\sqrt{ }$ \\
\hline Shop & $\sqrt{ }$ & & & & $\sqrt{ }$ & & & $\sqrt{ }$ & & $\sqrt{ }$ & \\
\hline Railway police station & $\sqrt{ }$ & $\sqrt{ }$ & & & & & $\sqrt{ }$ & $\sqrt{ }$ & $\sqrt{ }$ & & $\sqrt{ }$ \\
\hline $\begin{array}{c}\text { EV_CS-EV charging } \\
\text { points }\end{array}$ & $\sqrt{ }$ & & & & & & & $\sqrt{ }$ & & & \\
\hline $\begin{array}{l}\text { News stands } \\
\text { PO-Post Office }\end{array}$ & $\sqrt{ }$ & & & $\sqrt{ }$ & & $\sqrt{ }$ & $\sqrt{ }$ & $\sqrt{ }$ & $\sqrt{ }$ & $\sqrt{ }$ & \\
\hline SM-Supermarkets & $\sqrt{ }$ & & & $\sqrt{ }$ & & & & $\sqrt{ }$ & & $\sqrt{ }$ & \\
\hline
\end{tabular}

It is worth noting that all the stations present at least a bar inside them or in their extreme proximity. Bicycle parking (but not ad-hoc bicycle storage) and car parking are also widespread. Other services like supermarkets and shops, on the other hand, are not quite common. What many stations lack are instead EV charging points, with only two stations offering them.

\section{Station Attractiveness Evaluation: Gravity Indicator}

To evaluate the rail stations in the most objective way possible, a quantitative indicator was implemented. This indicator introduces a numerical measure to define the attractiveness of a rail stations, taking as inputs the services available around the station as well as their relative distance from the station. This score allows an explicit comparison between two or more stations, which is fundamental in a large-scale evaluation like the one that is presented in this work.

\subsection{Gravity-Based Models}

The indicator was developed starting from the available literature regarding GravityBased Accessibility Measures (also known as GRAbaM) [42]. This indicator is generally used in evaluating accessibility of a specific area, taking as inputs the number of opportunities present in the area and the cost (in terms of time or money) of moving from the starting point to that area. The usual formulation of a gravity-based measure can be expressed as follows [25]:

$$
A_{i, j}^{p}=\sum_{j} g\left(W_{j, k}\right) \cdot f\left(c_{i j}^{p}\right)
$$

where the Accessibility $A_{i j}^{p}$ of location $j$ is computed considering a standpoint of origin $i$, the potential $W$ of type $k$ at location $j$ and the cost of moving $C_{i j}$ between $i$ and $j$ as 
perceived by user $p$. The kernel $f(\cdot)$ is an appropriate impedance function, typically an exponential decay. It is possible to define two types of accessibility, namely active and passive accessibility. Active accessibility shows the potential of reaching, from a starting zone, the activities located in all the other zones of the study area, passive accessibility of a zone shows the ease of being reached from all the potential users of the other zones.

The number $W$ represents the number of opportunities of the zone in the case of active accessibility, while in the case of passive accessibility it represents the number of potential users in the zone, such as the resident population in the area. Table 3 shows an example of theoretical formulas of active and passive accessibility evaluation.

Table 3. Examples of theoretical formulas of active and passive accessibility.

\begin{tabular}{cc}
\hline & Example \\
\hline Active accessibility & $A c c(i)=\sum_{j} j o b s_{i}{ }^{\alpha} \cdot \exp \left(-\beta \cdot c_{i j}\right)$ \\
Passive accessibility & $A c c(i)=\sum_{j} \operatorname{res}_{i}{ }^{\alpha} \cdot \exp \left(-\beta \cdot c_{i j}\right)$ \\
\hline
\end{tabular}

Gravity based model are effective measures to evaluate the accessibility of a specific zone with respect to the other surrounding zones.

\subsection{Adapting a GRABAM Model to the Case Study}

The gravity measure presented in the literature is not suitable in the context of attractivity of a rail station. One of the aims of this research is to estimate the level of attractiveness of a certain station starting from the number and the type of services that are present nearby and the distance of each of these services from the station.

Therefore, the gravimetric measure was elaborated into the following Equation (2):

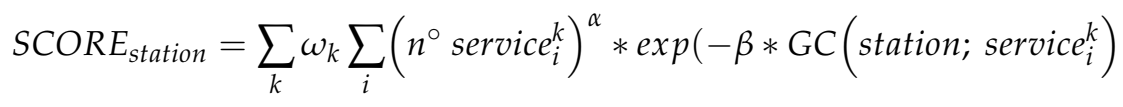

where:

- $n^{\circ}$ service $_{i}^{k}=$ number of services of type $k$ around the rail station.

- $G C=$ generalized travel cost: average distance from station to service $e_{i}^{k}$. Expressed in $\mathrm{km}$.

- $\alpha=$ weight to be calibrated.

- $\beta=$ weight to be calibrated.

- $\omega_{k}=$ weight based on the relevance of the service of type $k$ among the other types.

This edited form takes into account the number of services present in proximity of the rail station, elevates it at a specific exponent, and finally multiplies it by a negative exponential impedance function that takes as input the distance (in $\mathrm{km}$ ) of each service from the station. Therefore, this expression can weight more the presence of a higher number of services in the station surroundings and, at the same time, it reduces the importance of the service as its distance from the station grows. Finally, the partial scores are inserted in a weighted average that allows to highlight some types of services more than others.

Although the focus of the work is to identify and evaluate the presence of services within $15 \mathrm{~min}$, the services beyond this threshold were analyzed too. In fact, the services outside the $15 \mathrm{~min}$ isochrone now could potentially be included in the future as mobility improvement, so it is important to not exclude all of them.

This measure allows to assign a precise numeric score to each station of this study, allowing to evaluate its capability to be an attraction pole for the surrounding territory.

\subsection{Calibrating the Indicator}

To obtain meaningful results from the indicator, it is crucial to calibrate the parameters, namely $\alpha, \beta$ and the $\omega_{k}$ weights. If they are not properly chosen, the three parameters can 
yield largely skewed results and would not be representative of the actual situation of the urban context.

\subsubsection{The Alpha Parameter}

The alpha $(\alpha)$ parameter represent the exponent at which the number of services of each kind is elevated to. To understand the logic behind the choice of this value it is necessary to ponder on the perceived utility of a user about the services surrounding the rail station. The number of services existing near the station can affect the attractiveness of the place positively, both for the train users and the residents that live nearby. Therefore, a relationship between the number of services of a certain kind and the perceived utility of the user has to be established.

It can be established that a higher number of services would correspond to a higher amount of perceived utility. However, this proportionality is not necessarily linear. In fact, above a certain threshold, a further increase of the number of services available could not translate into an identical increase in utility felt by the user. Therefore, a non-linear relationship between these two variables can be identified.

Among all the possible non-linear functions, a root function could be reasonably adapted to describe this behaviour. As the number of services of a certain typology starts to increase, the perceived utility of the user rises significantly. However, as more services are being added, the overall utility starts to saturate, behaving in a less-than-proportional trend.

The choice of the $\alpha$ parameter must be appropriately done depending on the type of service that is being considered. The behaviour of the curve becomes more and more like a linear relationship whenever $\alpha$ approaches to 1 .

For each type of service present nearby the railway station the same analysis has been managed. First, a distinction between essential services (such as hospitals, schools or supermarkets) and additional services (such as cinemas or libraries) has been performed. After that, several services of the same type have been chosen as a threshold above which the increment in utility for the user becomes small enough. This was realised analysing the traffic flow of each station and considering an average number of users that may use that specific service. As last step, an appropriate $\alpha$ has been chosen that could resemble this user perception.

In Table 4 different values of some stations are provided. For each station is reported the passengers flow of a normal working day, the minimum number of services of some typologies and the chosen value of $\alpha$. The traffic flow data allowed to distinguish large (Lambrate, Rogoredo and Monza), medium (Como, Lodi, Pioltello) and small (Iseo) stations, representing an additional parameter that contributes to define $\alpha$.

Table 4. Some examples of threshold number of services for different railway stations. The choice of alpha depends on the chosen threshold and on the traffic flow.

\begin{tabular}{cccccccc}
\hline \multicolumn{7}{c}{ Marginal Utility Threshold } \\
\hline $\begin{array}{c}\text { Railway } \\
\text { Station }\end{array}$ & Daily Pax. Flow & H & PO & SM & L & Cafe & EV_CS \\
\hline L & 46,704 & 2 & 3 & 3 & 1 & 8 & 10 \\
I & 25,218 & 2 & 3 & 3 & 1 & 8 & 10 \\
H & 15,823 & 2 & 3 & 3 & 1 & 8 & 10 \\
B & 2773 & 2 & 2 & 3 & 1 & 4 & 5 \\
D & 1580 & 2 & 2 & 3 & 1 & 4 & 5 \\
A & 1089 & 2 & 2 & 3 & 1 & 4 & 5 \\
C & 317 & 1 & 1 & 3 & 1 & 2 & 5 \\
\multicolumn{2}{c}{ a_large_station } & 0.3 & 0.4 & 0.4 & 0.2 & 0.55 & 0.55 \\
\multicolumn{2}{c}{ a_small_station } & 0.3 & 0.3 & 0.4 & 0.2 & 0.45 & 0.45 \\
\end{tabular}

A = Como; B = Lodi; C = Iseo; D = Pioltello; E = Treviglio; F = Vigevano; G = Gallarate; H = Monza; L = Milano Lambrate; $\mathrm{M}=$ Milano Bovisa. 


\subsubsection{The Beta Parameter}

The beta $(\beta)$ parameter represents the rate of decrement of the impedance function with respect to growth of the distance from the station. A small value of $\beta$ will have a lower damping effect on the score contribution of each service, while a higher $\beta$ would attenuate it more. Literature generally values this parameter equal to 1 [42].

\subsubsection{The Omega Parameter}

The $\omega_{k}$ weight are the parameters that contribute to favour the score of some types of services over some others. Each single $\omega_{k}$ was selected depending on the relevance of each service with respect to the city context. The presence of essential activities near the station, such as hospitals or schools, was favoured with higher weights, for instance, it can be considered 10 for the first and 3 for the latter. Whereas other subsidiary services, such as bars or libraries, have been assigned to a lower value, such as 1 for libraries and cafes and 2 for supermarkets or cinemas.

The choice of the weight thus relies on the importance of the service and the number of clients or users that it can manage at any moment. For instance, a hospital or a theatre have larger capability of attracting people not only in the city they lie in but also from external urban areas. A bar or a library instead relies more on the local demand.

\subsection{Indicator Implementation}

The indicator introduced in previous section has been implemented using QGIS software and the programming language Python. First, the number of services around the station was obtained. This was realised counting the total number of activities within the town border or, in the case of Milan, within a $2 \mathrm{~km}$ radius from the station. Secondly, the use of a particular QGIS plug-in called ORS Tools allowed to obtain a list of the distances from the station to each service of a specific type. Subsequently, the partial score was computed for each type of activity. Finally, the total score of the station was calculated as the sum of the partial score.

\section{Analysis and Discussion of Results}

The method described was adopted for all the stations analysed, leading to interesting results. As a remark, the score is used to define how much a station can be attractive thanks to the services that are developed inside and around it. As a preliminary analysis, higher scores are expected from the stations inserted in larger and denser urban areas, while lower scores in the ones present in smaller and less dense zones. In Figure 7, the results performed are shown.

As it is possible to see in Figure 7, there are two stations with a score much higher than the others. These two stations are Milano Lambrate and Monza, whose score are almost four times bigger with respect to the highest score of the other stations. The cities with lower scores are Iseo, Pioltello, Treviglio and Vigevano.

After having obtained the scores, they were normalized both between 0 and 1 and using mean and standard deviation as shown in Figure 8, allowing to better understand the proportions of the scores between the cities. 


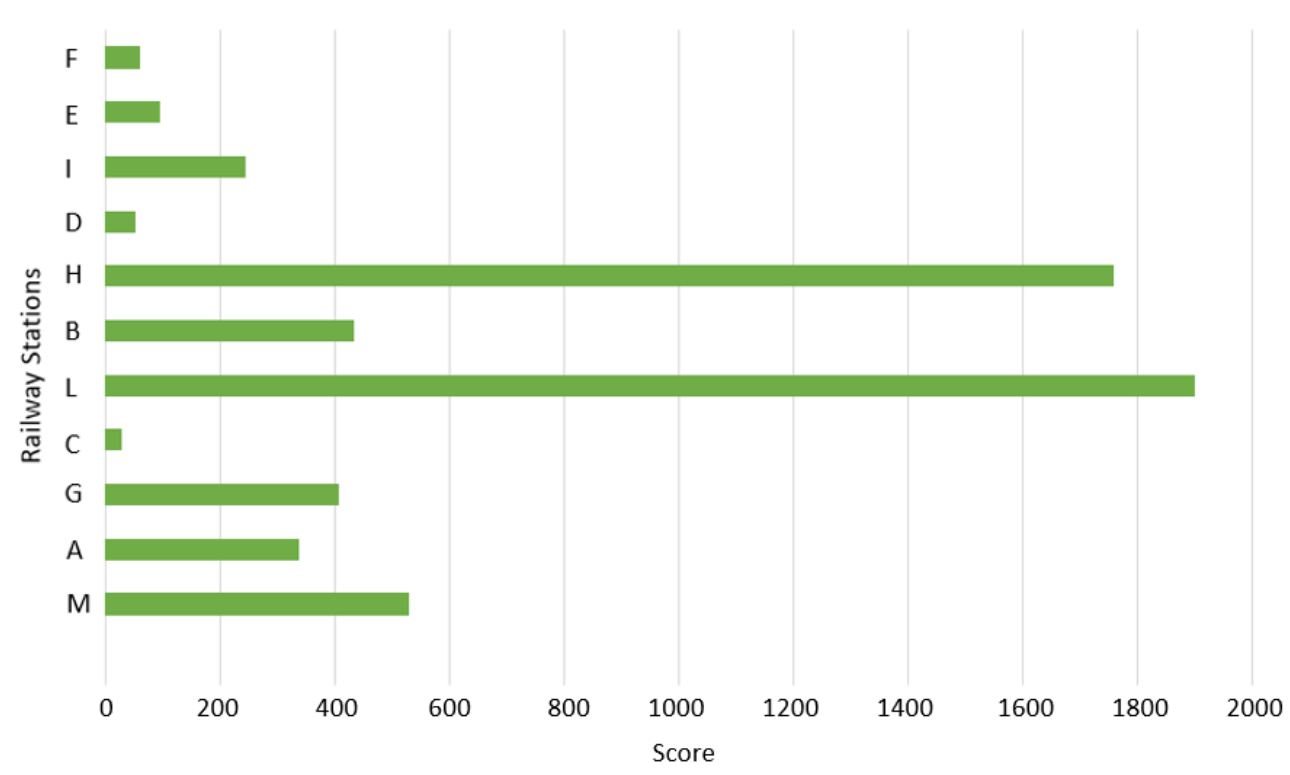

Figure 7. Score obtained using gravimetric measures for the 11 railway stations analyzed.

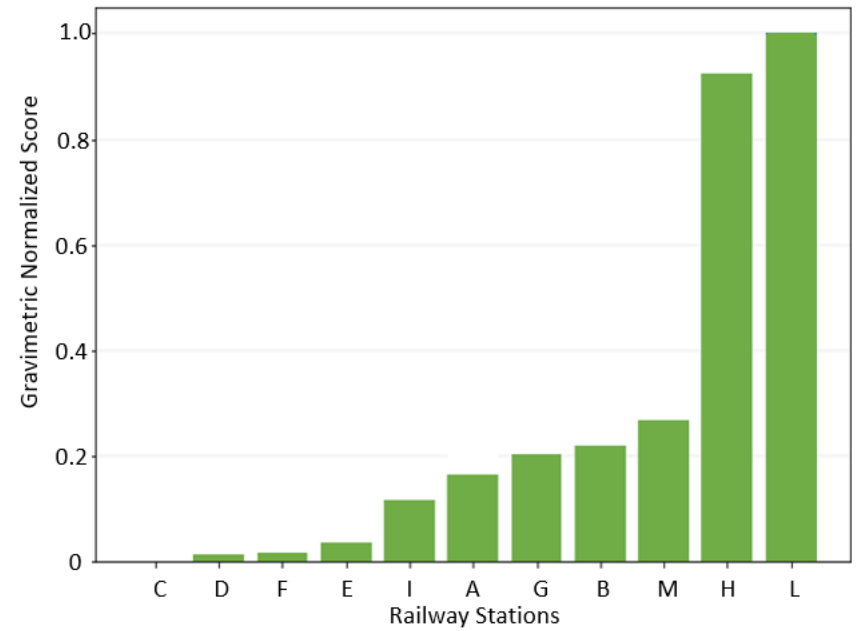

Figure 8. Normalized scores [between 0 and 1] for the 11 railway stations analysed.

The ranking established by the gravity measure was not difficult to forecast in the initial part of the study. As a matter of fact, the stations with the highest scores are also the biggest and they are located in the centre of metropolitan areas of Milan, for Lambrate station and Monza, for the homonymous station.

The element that probably requires a higher degree of exploration is the analysis of the reasons why these two stations have a score that is almost four times bigger with respect to the others. To find an answer to this question an elaboration was performed, focusing on two different elements. The first is the comparison of the services present in each station, while the second is an analysis on the relationship between the station and the traffic flow.

To explain the situation in a clearer way, all the services around the stations were represented in Figure 9, where a better explanation of why the scores are so different could emerge. Observing the graph, the first possible statement to make is that close to Lambrate and Monza stations (dark red and yellow bars) there are many more services of each category with respect to the stations located in the other cities. This trend is different only in few exceptions like EV charging stations, where Como leads the trend or café, where Bovisa gets a good result. 


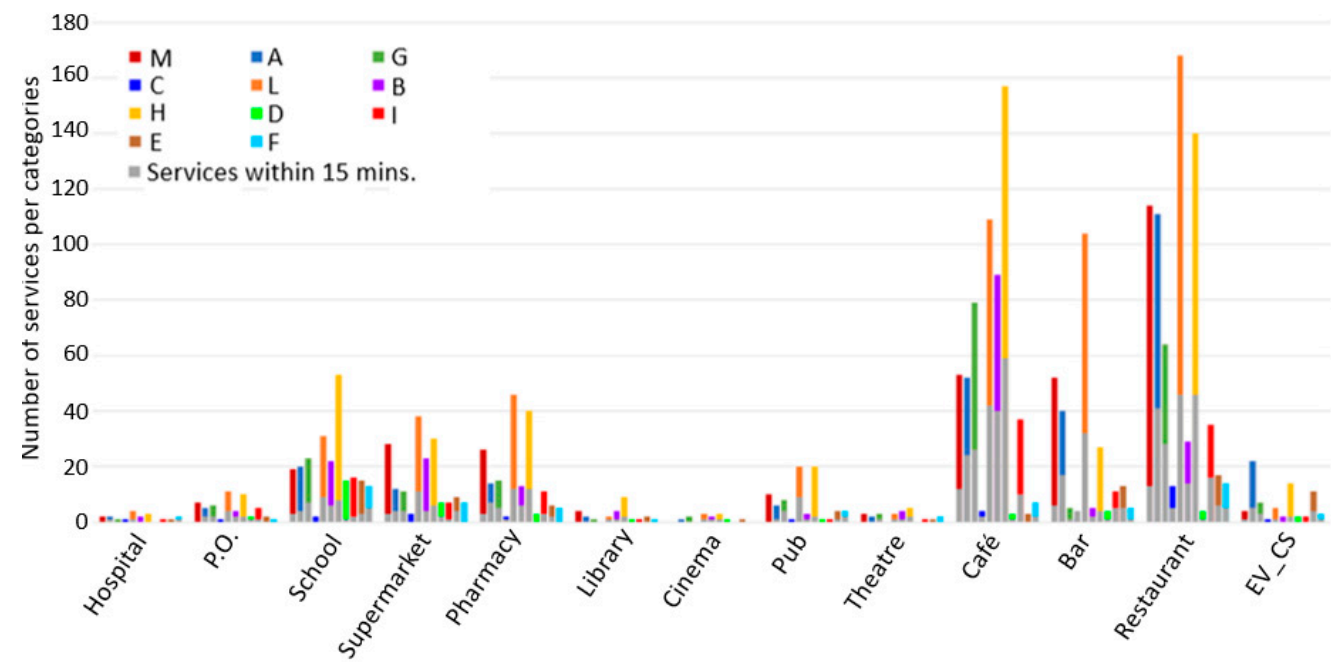

Figure 9. Number of services in each station, grouped by typology. Grey bars indicate services within $15 \mathrm{~min}$.

This result is due to two main reasons: the first, as expected, is that larger and denser cities have a greater availability of services. The second considers the methodology of the analysis: as explained before, the availability of services collected in the stations of Milan has been selected within a $2 \mathrm{~km}$ radius around the station. This was realised to explicitly set a boundary limit to avoid considering all the services of the entire city of Milan, creating even more a disproportionate result.

From Figure 9, it can be also noticed that the number of cafes, restaurants and bar is much higher in Lambrate and Monza. To look easily on the other categories of services, Figure 10, where cafes, bars and restaurants were removed can be observed to have a clearer view of the distribution of the remaining services.

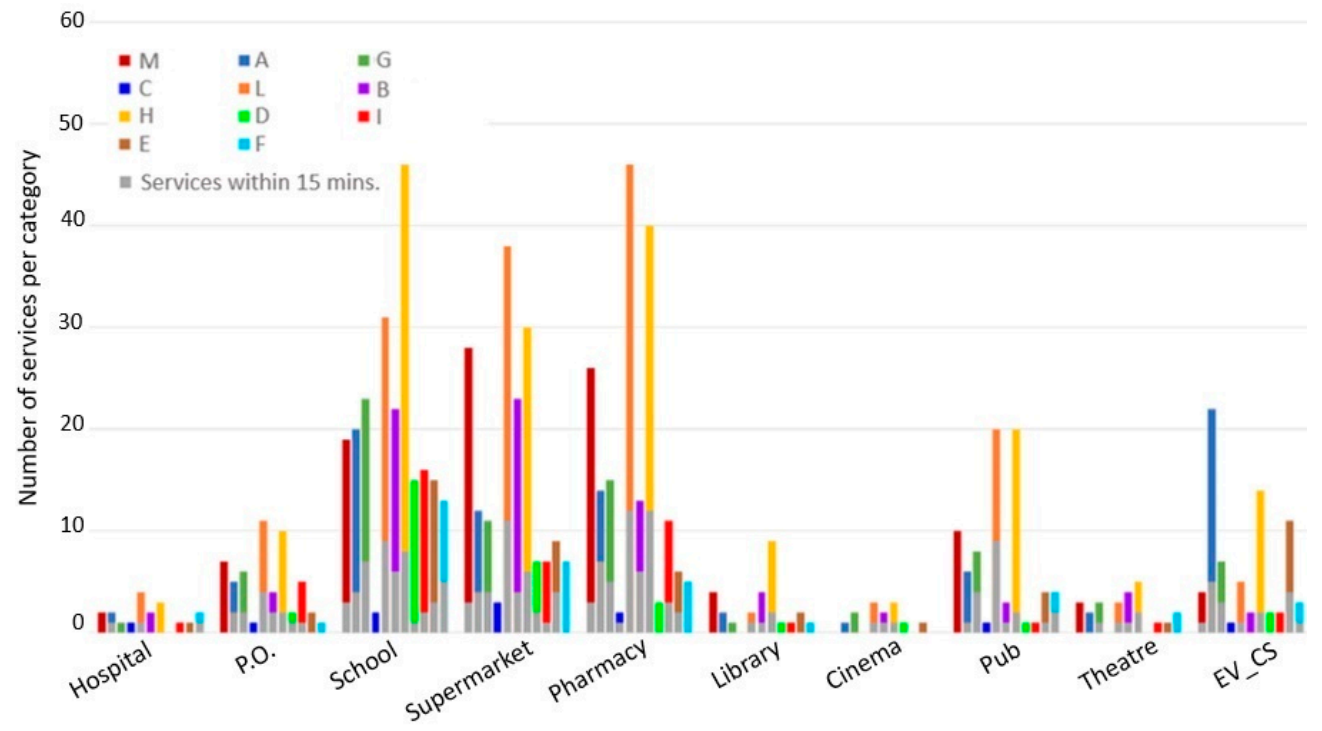

Figure 10. Distribution of services around the station excluding cafes, bars and restaurants.

The trend noticed for bars, restaurants and cafes remain clearly the same also for all other categories. Larger and denser cities still remain the winners in this analysis.

Considering the stations that had a low score, the services available in them are much less than in larger cities. Moreover, the score of little stations remained small even after the calibration of the gravimetric measure based on the dimension of the station. 
This first analysis of the results of the score, through the analysis of the services, shows that the score well fits the situation of each station and their tendency to attract people thanks to the presence of a different number of services.

The following analysis deals with the relationship between the number of passengers that each day reach the stations and the score that was computed for each of them. Figure 11 represents the two normalized quantities in the same plot (values fitted between 0 and 1).

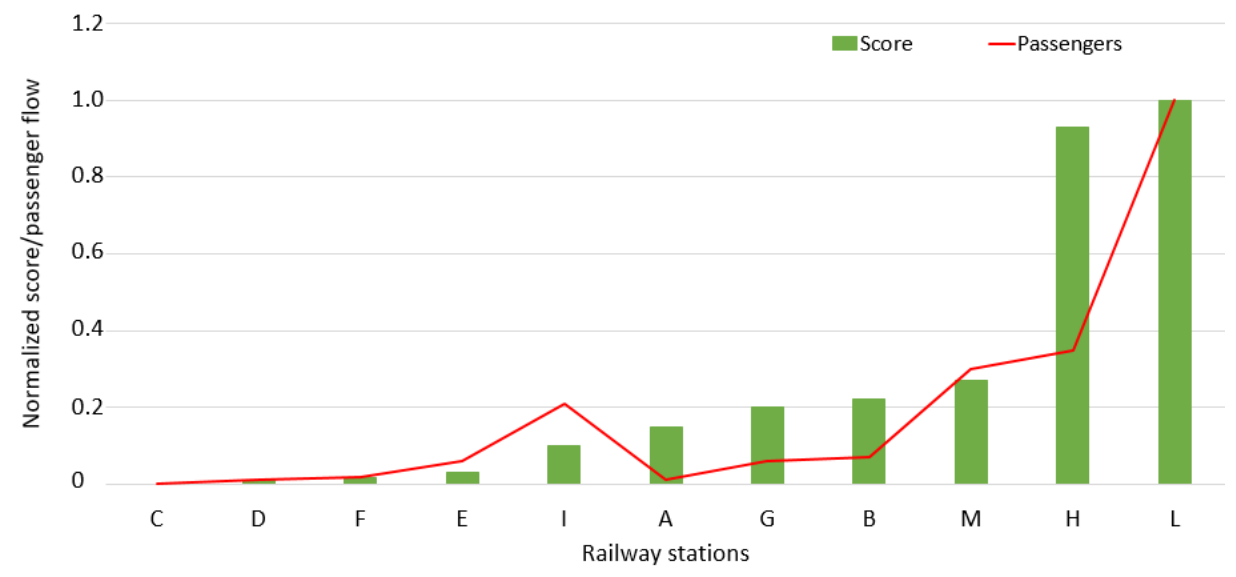

Figure 11. Normalized scores and passenger flows for each railway station analysed.

As it can be seen, the values of the score follow well the variation in the number of daily passengers attracted by each station. Stations with bigger traffic flow get a higher service score while the smaller ones get a lower score. This graph can be considered as a sort of validation of the score model.

Thanks to this evidence, it is possible to state that the score computed for different stations, considering the service present and their relative distance, is able to represent how well the station is able to attract passenger demand.

Moreover, the ratio between the number of passengers and the score was calculated for each station, as shown in Figure 12. This graph shows how many passengers there are for each point of score generated by the available services. Thus, stations that have to deal with fewer passengers also present few services, while a higher number of services around bigger stations is well justified by high traffic flows (see Monza and Lambrate). The ratio is constant in most of the station, with the only exception represented by Milano Rogoredo, in which 102 passengers per score point was found. This result tells that Rogoredo does not offer enough services compared to its high traffic volume.

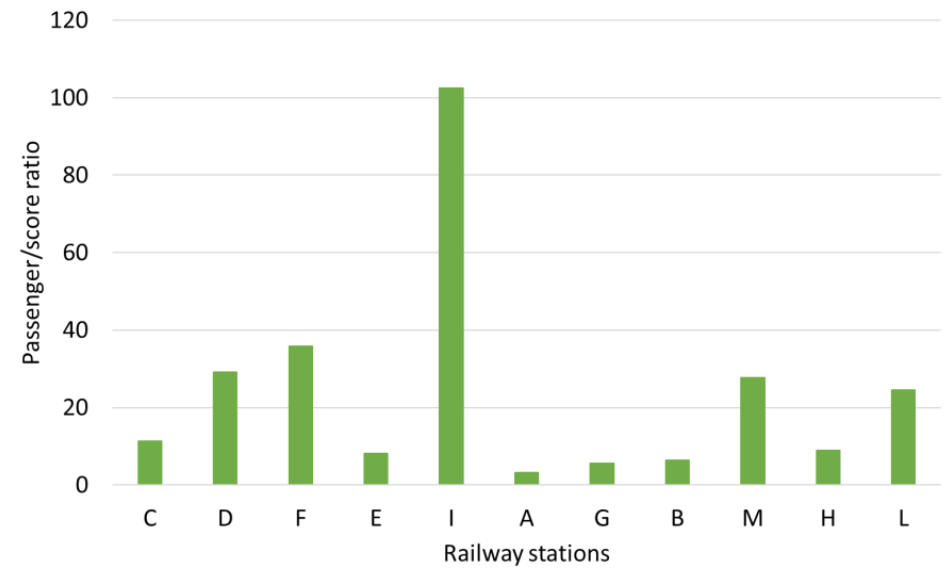

Figure 12. Ratio between passenger's flow and score, showing how many passengers the station attracts for each point of score obtained. 


\section{Conclusions}

The idea of 15-min cities seems to have awaked and stimulated planners' imagination and politicians' willingness for providing new planning opportunities. During COVID-19 crisis when the need for imagining the post-pandemic city emerged, 15-min cities came into focus as an urban development model for the economic recovery of cities through a more egalitarian and socially inclusive perspective. However, it is to be specified the fact that the "15-min city" concept has to be seen as a "guiding principle" and not as a "fit for all" idea, since it has to be applied according to the different contexts and cities' characteristics.

Looking at the projects currently under development, the "15-min city" concept has been mainly carried out in non-standard areas of the cities, without a clear unique vision. In this work instead, the zone's boundaries were pre-defined to be within $15 \mathrm{~min}$ far from

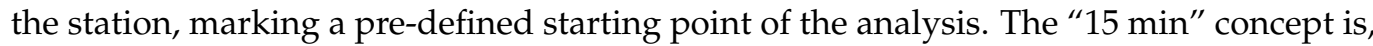
in reality, quite flexible and should therefore be adapted in each city or town is applied in.

A reorganization of the stations and their surroundings can be a win-win solution both for the stations themselves that could become the central pole of the neighborhood, and local residents that will feel an added value. Moreover, innovative services and facilities in the station could let local demand and local offer meet, especially with the help of digital platform and smarter ways to sell services and products to the customers. Finally, trains are one of the most environmentally friendly mode of transport for very large amount of people and goods, making them a potential game changer for the shift towards sustainable mobility.

The final goal of this project was to introduce a tool aimed at synthesizing and evaluating in quantitative terms the conformity of an area according to the "15-min city" concept. Once calculated, the indicator could be also useful for the decision maker to understand which interventions should be put in place to make aware choices. In any case, all the interventions proposed should be compliant with the cities' context and opportunities. The indicator's main strength is its reproducibility in all circumstances and conditions, even if the centroid of the analysis is moved away from the station and applied to some other locations. The results provided by the indicator can become as more precise as the quality and availability of the input data increases. Finally, some proposals on the possible interventions that could be done in the stations were reported. This intervention should be seen as useful complements of a larger vision for the station that is now seen as a multifunctional point of interest for the urban context.

Author Contributions: Conceptualization, F.B. and M.L.; methodology, F.B., C.G.C. and M.L.; software, C.G.C.; validation, F.B. and M.L.; formal analysis, C.G.C.; investigation, F.B.; resources, M.L.; data curation, C.S.; writing-original draft preparation, F.B. and M.L. supervision, F.B. and M.L.; project administration, R.M., L.C. (Luigi Contestabile) and L.C. (Leonardo Cesarini). All authors have read and agreed to the published version of the manuscript.

Funding: This research received no external funding.

Institutional Review Board Statement: Not applicable.

Informed Consent Statement: Not applicable.

Data Availability Statement: Not applicable.

Conflicts of Interest: The authors declare no conflict of interest.

\section{References}

1. Sisson, P. What is a 15-Minute City? Available online: https:/ / citymonitor.ai/environment/what-is-a-15-min-city (accessed on 3 September 2021).

2. C40 Cities Climate Leadership Group. How to Build Back Better with a 15-Minute City. Available online: https://www.c4 0knowledgehub.org/s/article/How-to-build-back-better-with-a-15-min-city?language=en_USway\%20of\%20life (accessed on 3 September 2021). 
3. Nižetić, S. Impact of coronavirus (COVID-19) pandemic on air transport mobility, energy, and environment: A case study. Int. J. Energy Res. 2020, 44, 10953-10961. [CrossRef]

4. Allam, Z. (Ed.) Chapter 1-The first 50 days of covid-19: A detailed chronological timeline and extensive review of literature documenting the pandemic. In Surveying the COVID-19 Pandemic and Its Implications; Elsevier: Amsterdam, The Netherlands, 2020; pp. 1-7.

5. Moreno, C.; Allam, Z.; Chabaud, D.; Gall, C.; Pratlong, F. Introducing the "15-Minute City": Sustainability, Resilience and Place Identity in Future Post-Pandemic Cities. Smart Cities 2021, 4, 93-111. [CrossRef]

6. Pozoukidou, G.; Chatziyiannaki, Z. 15-Minute City: Decomposing the New Urban Planning Eutopia. Sustainability 2021, 13, 928. [CrossRef]

7. Balletto, G.; Ladu, M.; Milesi, A.; Borruso, G. A Methodological Approach on Disused Public Properties in the 15-Minute City Perspective. Sustainability 2021, 13, 593. [CrossRef]

8. Graells-Garrido, E.; Serra-Burriel, F.; Rowe, F.; Cucchietti, F.M.; Reyes, P. A city of cities: Measuring how 15-min urban accessibility shapes human mobility in Barcelona. PLoS ONE 2021, 16, e0250080. [CrossRef]

9. Lehmann, S. Advocacy for the compact, mixed-use and walkable city: Designing smart and climate resilient places. Int. J. Environ. Sustain. 2016, 5, 1-11. [CrossRef]

10. European Commission; Directorate-General for Mobility and Transport. Sustainable Urban Mobility: European Policy, Practice and Solutions; European Union: Brussels, Belgium, 2017; Catalogue Number MI-02-16-275-EN-N; ISBN 978-92-79-66651-3. [CrossRef]

11. Coppola, P.; Dell'Olio, L.; Ibeas Portilla, A. Rediscovery the social role of transport infrastructures. Transp. Res. Part A Policy Pract. 2019, 125, 169-170. [CrossRef]

12. Transport Planning and Other Disciplines: Better Together. Available online: https://tps.org.uk/public/downloads/dBAzz/ Natasha\%20\%20Smithson\%20-\%20Final\%20Paper.pdf (accessed on 3 September 2021).

13. Cascetta, E. Transport Systems Analysis: Models and Applications; Springer: New York, NY, USA, 2009. [CrossRef]

14. Kane, L.; Del Mistro, R.F. Changes in transport planning policy: Changes in transport planning methodology? Transportation 2003, 30, 113-131. [CrossRef]

15. Allam, Z. On culture, technology and global cities. In Cities and the Digital Revolution: Aligning Technology and Humanity; Springer International Publishing: Cham, Switzerland, 2020; pp. 107-124.

16. Wimbadi, R.W.; Djalante, R.; Mori, A. Urban experiments with public transport for low carbon mobility transitions in cities: A systematic literature review (1990-2020). Sustain. Cities Soc. 2021, 72, 103023. [CrossRef]

17. Richards, G. Cultural tourism: A review of recent research and trends. J. Hosp. Tour. Manag. 2018, 36, 12-21. [CrossRef]

18. Ravazzoli, E.; Torricelli, G.P. Urban mobility and public space. A challenge for the sustainable liveable city of the future. J. Public Space 2017, 2, 37-50. [CrossRef]

19. Salingaros, N.A. Complexity and urban coherence. J. Urban Des. 2000, 5, 291-316. [CrossRef]

20. Batty, M.; Besussi, E.; Chin, N. Traffic, Urban Growth and Suburban Sprawl; CASA: New York, NY, USA, 2003.

21. Brueckner, J.K. Urban sprawl: Diagnosis and remedies. Int. Reg. Sci. Rev. 2000, 23, 160-171. [CrossRef]

22. Glaeser, E.L.; Kahn, M.E. Sprawl and urban growth. In Handbook of Regional and Urban Economics; Elsevier: Amsterdam, The Netherlands, 2004; Volume 4, pp. 2481-2527.

23. Bento, A.M.; Cropper, M.L.; Mobarak, A.M.; Vinha, K. The effects of urban spatial structure on travel demand in the United States. Rev. Econ. Stat. 2005, 87, 466-478. [CrossRef]

24. Anderson, W.P.; Kanaroglou, P.S.; Miller, E.J. Urban form, energy and the environment: A review of issues, evidence and policy. Urban Stud. 1996, 33, 7-35. [CrossRef]

25. Gordon, P.; Kumar, A.; Richardson, H.W. The influence of metropolitan spatial structure on commuting time. J. Urban Econ. 1989, 26, 138-151. [CrossRef]

26. Muñiz, I.; Galindo, A. Urban form and the ecological footprint of commuting. The case of Barcelona. Ecol. Econ. 2005, 55, 499-514. [CrossRef]

27. Ewing, R.; Hamidi, S. Compactness versus sprawl: A review of recent evidence from the United States. J. Plan. Lit. 2015, 30, 413-432. [CrossRef]

28. Kirkley, A.; Barbosa, H.; Barthelemy, M.; Ghoshal, G. From the betweenness centrality in street networks to structural invariants in random planar graphs. Nat. Commun. 2018, 9, 1-12. [CrossRef]

29. Artmann, M.; Kohler, M.; Meinel, G.; Gan, J.; Ioja, I.C. How smart growth and green infrastructure can mutually support each other A conceptual framework for compact and green cities. Ecol. Indic. 2019, 96, 10-22. [CrossRef]

30. Krizek, K.J. Residential relocation and changes in urban travel: Does neighborhood-scale urban form matter? J. Am. Plan. Assoc. 2003, 69, 265-281. [CrossRef]

31. Zhang, W.; Zhao, Y.; Cao, X.; Lu, D.; Chai, Y. Nonlinear effect of accessibility on car ownership in Beijing: Pedestrian-scale neighborhood planning. Transp. Res. Part D Transp. Environ. 2020, 86, 102445. [CrossRef]

32. Nitti, M.; Pinna, F.; Pintor, L.; Pilloni, V.; Barabino, B. Iabacus: A wi-fi-based automatic bus passenger counting system. Energies 2020, 13, 1446. [CrossRef]

33. Wheeler, S. Planning for Sustainability: Creating Livable, Equitable, and Eco-Logical Communities; Routledge: London, UK; New York, NY, USA, 2013. 
34. Veneri, P. Urban Spatial Structure in OECD Cities: Is Urban Population Decentralising or Clustering; Organisation for Economic Cooperation and Development: Paris, France, 2015.

35. Brezzi, M.; Veneri, P. Assessing polycentric urban systems in the OECD: Country, regional and metropolitan perspectives. Eur. Plan. Stud. 2015, 23, 1128-1145. [CrossRef]

36. Cocchia, A. Smart and digital city: A systematic literature review. In Smart City; Springer International Publishing: Cham, Switzerland, 2014; pp. 13-43.

37. Cervero, R.; Kockelman, K. Travel demand and the 3ds: Density, diversity, and design. Transp. Res. Part D Transp. Environ. 1997, 2, 199-219. [CrossRef]

38. Bongardt, D.; Stiller, L.; Swart, A.; Wagner, A. Sustainable Urban Transport: Avoid-Shift-Improve (A-S-I). Transformative Urban Mobility Initiative. 2019. Available online: https://www.transformative-mobility.org/assets/publications/ASI_TUMI_SUTP_ iNUA_No-9_April-2019.pdf (accessed on 15 July 2021).

39. Borghetti, F.; Bozza, I.; Maja, R.; Malavasi, G.; Ricci, S.; Rizzetto, L. Unplanned rail service disruptions: Recovery index for the station analysis where to set up a bus bridging. Ing. Ferrov. 2020, 75, 813-839.

40. Flussi Stazioni Ferroviarie. Available online: www.dati.lombardia.it/Mobilit-e-trasporti/Flussi-Stazioni-Ferroviarie/m2u2-frtq (accessed on 10 September 2020).

41. $15^{\circ}$ Censimento della popolazione e delle abitazioni 2011. Available online: https://www.istat.it/it/censimenti-permanenti/ censimenti-precedenti/popolazione-e-abitazioni/popolazione-2011 (accessed on 13 September 2021).

42. Páez, A.; Scott, D.M.; Morency, C. Measuring accessibility: Positive and normative implementations of various accessibility indicators. J. Transp. Geogr. 2012, 25, 141-153. [CrossRef] 